\title{
Altered Hemispheric Asymmetry of Auditory Magnetic Fields to Tones and Syllables in Schizophrenia
}

\author{
Brigitte Rockstroh, Johanna Kissler, Bettina Mohr, Carsten Eulitz, Ursula Lommen, \\ Christian Wienbruch, Rudolf Cohen, and Thomas Elbert
}

Background: A growing body of literature suggests that schizophrenic patients often do not show the normal brain hemispheric asymmetry. We have found this for simple tones presented to the right ear in a previous study. In this study we extended this investigation to left ear stimulation and verbal stimuli.

Methods: With a whole-head neuromagnetometer, contra- and ipsilateral auditory-evoked magnetic fields in response to tones $(1000 \mathrm{~Hz}$ ) and to the syllables ("ba") delivered to the left and right ears in separate runs were compared between schizophrenic patients $(\mathrm{n}=17)$ and healthy control subjects $(\mathrm{n}=15)$.

Results: In response to tones, all control subjects showed the expected asymmetry (contralateral predominance) of the auditory-evoked magnetic N100m (dipole moment). In the patient sample asymmetry was reversed following tones presented to the left ear in $47 \%$ and following tones to the right ear in $24 \%$. In response to syllables, the asymmetry was similar between groups. In patients compared with control subjects the N100m was located more anterior without asymmetry between hemispheres.

Conclusions: Results suggest that deviation from the normal functional lateralization in schizophrenia appears in a proportion of patients at a basic stage of auditory processing, but may be compensated for at higher levels such as the processing of syllables. Biol Psychiatry 2001; 49:694-703 (C) 2001 Society of Biological Psychiatry

Key Words: Schizophrenia, magnetoencephalography, hemispheric asymmetry, N100m, syllables, auditory, verbal processing, tone perception

\section{Introduction}

$\mathrm{M}$ any studies have shown an altered hemispheric asymmetry in schizophrenic patients in terms of structure and in terms of function (Bilder et al 1999; DeLisi 1999; Flor-Henry 1989; Galderisi et al 1999; Pearlson and Marsh 1999; Rockstroh et al 1997). Morphometric data indicate reduced or reversed asymmetry,

From the Department of Psychology, University of Konstanz, Konstanz, Germany. Address reprint requests to Brigitte Rockstroh, Ph.D., University of Konstanz, Department of Psychology, P.O. Box D23, D-78457 Konstanz, Germany. Received May 12, 2000; revised July 26, 2000; accepted July 28, 2000. particularly of temporal lobe structures (i.e., planum temporale) of the left hemisphere (Barta et al 1997; Falkai et al 1995; Petty et al 1995), a brain region strongly involved in language processing (Geschwind and Levitzky 1968). Nonetheless, gross structural deviations occur only in a minority of patients, which may be a result of different ways of assessing the anomalies. Moreover, the relation between structural deviations in cerebral asymmetry and functional lateralization is still unclear. Studies investigating functional lateralization complement structural findings and should validate hypotheses of abnormal asymmetry underlying basic schizophrenic symptoms, as postulated, for instance, by Crow (1990, 1997a, 1998). Alterations in the functional lateralization were, for instance, reported by Gur (1978), indicating a left hemispheric deficit when schizophrenic patients had to process visually presented syllables. In a magnetic resonance imaging (MRI) study, Woodruff and colleagues (Woodruff et al 1997) compared activation during listening to external speech with activation during blank intervals and found greater right temporal and less left posterior activation in schizophrenic patients relative to control subjects. However, other studies found normal patterns of functional asymmetry in schizophrenic patients during language processing (Magaro and Chamrad 1983; Mohr et al, in press). Noninvasive imaging techniques such as functional MRI, electroencephalography (EEG), and magnetoencephalography (MEG) have substantiated the knowledge of functional hemispheric asymmetry. In this respect, the auditory modality has been favored, as various acoustic stimuli elicit auditory-evoked magnetic fields (AEFs) in the supratemporal auditory cortex in the temporal lobes, which display distinct hemispheric asymmetries (Mäkelä et al 1993; Reite et al 1999). Lateralized AEFs have been found for the processing of tones (Mäkelä et al 1993; Pantev et al 1998) and phonetic stimuli (Eulitz et al 1995; Gootjes et al 1999), with the larger evoked magnetic responses in temporal areas contralateral to the stimulated ear. In schizophrenic patients, MEG studies revealed reversed (Tiihonen et al 1998) or reduced (Reite et al 1997, 1999; Rockstroh et al 1998; Sauer et al 1998) functional asymmetry of the N100m, the magnetic audi- 
tory-evoked response peaking around $100 \mathrm{msec}$ following monaural stimulation with simple tones. The commonly reported gender difference, with more pronounced functional hemispheric asymmetry in male subjects than in female subjects (Geschwind and Levitsky 1968; Hellige 1993; Kanno et al 1998; Witelson and Kigar 1992), seems to affect the alteration of lateralization in schizophrenic patients. For instance, Reite and colleagues (Reite et al 1997) reported a reduced asymmetry of the N100m component only in male schizophrenic patients. Sauer and colleagues (Sauer et al 1998) found dipole deviations in the $\mathrm{N} 100 \mathrm{~m}$ in the left hemisphere for male subjects and in the right hemisphere for female subjects (see also Hajek et al 1997; Kreitschmann-Andermahr et al 1999).

Until now, studies with schizophrenic patients looking at hemispheric differences have been restricted to the level of simple tone processing. As language processing is known to be predominant in the left hemisphere in most righthanded healthy subjects and has been shown to evoke left lateralized brain responses in the $\mathrm{N} 100 \mathrm{~m}$ component in MEG (Rinne et al 1999), it is of interest to examine whether this is true also for schizophrenic patients. Theories of abnormal lateralization in schizophrenia are based on the assumption that language processes are involved in the development of laterality per se as well as in the development of schizophrenic disorders (Crow 1997b; Crow et al 1989). Thus, language processes should be incorporated in experiments aiming at testing these theories. It still seems not sufficiently clear at which processing level altered asymmetry emerges in schizophrenia and for which processing levels or domains schizophrenic patients exhibit deviant or normal functional asymmetry. Is it only evident during passive processing of simple tones or is it also visible at higher processing stages like syllable processing or even word or sentence comprehension?

With this background, we examined hemispheric lateralization during a nonverbal (tone processing) and verbal (syllable processing) task. Auditory-evoked magnetic fields were measured in schizophrenic patients and healthy control subjects in response to tones and syllables delivered monaurally to the right or the left ear. These measurements should substantiate our previous results (Rockstroh et al 1998) and specify hemispheric asymmetry patterns in schizophrenic patients by looking at different processing levels including simple tones and acoustically more complex material like syllables.

\section{Methods and Materials}

\section{Subjects}

Seventeen inpatients (five female, mean age $32.2 \pm 6.2$ years, education $11.0 \pm 2.4$ years) of the university research ward at the local center of psychiatry were recruited for this study. Data of the patients were compared to those of 15 healthy subjects comparable to the patient group with respect to gender, age, and educational degree (six female, mean age $31.3 \pm 5.8$ years, education $11.6 \pm 2.0$ years). All subjects were paid (about $\$ 10$ ) for participation in the experiment, which lasted for about 2 hours.

The diagnoses according to DSM-IV were based on the answers given in the Present State Examination (PSE) (Wing et al 1974), clinical files, and extended personal contact with the patient, and were given by the psychiatrist of the ward. Patients met a DSM-IV diagnosis of either paranoid or disorganized schizophrenia. The extent of hospitalization varied between 1 and 515 weeks around a median of 21 weeks (mean $67.9 \pm 128.9$ weeks). All patients except one were under neuroleptic medication, 10 patients receiving standard neuroleptics and six atypical neuroleptics (mean daily dosage $234 \pm 186 \mathrm{mg}$ chlorpromazinequivalents). Patients with a diagnosis of a schizoaffective disorder or substance dependence were excluded, as were patients with a neurologic disorder or EEG or computed tomography abnormalities. The psychopathologic status on the day of the experimental investigation was assessed by the psychologist/ psychiatrist in charge by means of the Brief Psychiatric Rating Scale (Lukoff et al 1986; Overall and Gorham 1962; average score $43.8 \pm 6.8)$, the Scale for the Assessment of Negative Symptoms (SANS) (Andreasen 1981; average score $53.7 \pm 37.7$ ), and the Positive and Negative Symptom Scale (PANSS) (Kay et al 1987; PANSS-P, $15.8 \pm 6.4$; PANSS-N, $19.5 \pm 7.8$; PANSS-G, $35.7 \pm$ 7.2). Subjects who did not report any psychotropic medication and who had never been treated for neurologic or psychiatric disorders were accepted as control subjects. All subjects were right-handed, as assessed by the Edinburgh handedness questionnaire (Oldfield 1971). A normal audiologic status was assured in that air conduction thresholds of no more than $10 \mathrm{~dB}$ hearing level in the range from 250 to $8000 \mathrm{~Hz}$ were allowed.

\section{Design and Material}

In a passive listening task, two series of 128 tone bursts (carrier frequency $1000 \mathrm{~Hz}, 500-\mathrm{msec}$ duration, 10-msec rise and fall time, cosine function) and two series of 128 auditory presentations of the syllable "ba" were presented in balanced order across subjects. Syllables resembling a male voice were synthetic (Klatt Syntheziser), presented with 250-msec duration, a 45-msec transition period and with the fundamental frequency varying from $128 \mathrm{~Hz}$ at syllable onset to $109 \mathrm{~Hz}$ at syllable offset. All stimuli were presented monaurally either to the left or to the right ear. The loudness of the stimuli was $60 \mathrm{~dB}$ above the individually determined hearing level. Stimulus onset asynchrony varied between 2.7 and $3.3 \mathrm{sec}$ (pseudorandom order). Stimuli were presented through a nonmagnetic and echo-free stimulus delivery system with an almost linear frequency characteristic (deviations less than $\pm 4 \mathrm{~dB}$ in the range $200-4000 \mathrm{~Hz}$ ).

\section{Data Acquisition and Analysis}

For the measurement a lying position was chosen, as being more comfortable and ensuring that the subject did not move during the measurement. Subjects were asked to stay awake, to keep their eyes open, and to fixate the gaze onto a point on the 
chamber ceiling. Compliance was verified by video monitoring throughout the measurement. The stability of the head-sensor position was controlled by repeated measurements of the known positions of five indicator coils fixed on the scalp.

Auditory magnetic fields evoked by the different stimuli were recorded simultaneously from the left and the right hemisphere using a wholehead neuromagnetometer (MAGNES 2500, Biomagnetic Technologies, San Diego) installed within a magnetically shielded chamber (Vacuumschmelze, Hanau, Germany). The measuring surface of the sensor is helmet shaped and covers the entire cranium. Within the sensor 148 signal detectors (magnetometer type) are arranged in a uniformly distributed array spaced by $28 \mathrm{~mm}$.

Stimulus-related epochs of $1000 \mathrm{msec}$ (including a 200-msec prestimulus interval) were recorded with a bandwidth of 1-100 $\mathrm{Hz}$ and a sampling frequency of $387.5 \mathrm{~Hz}$. Epochs contaminated by muscle or eye blink artifacts comprising amplitude variations of more than $5 \mathrm{pT}$ in any channel were automatically rejected from averaging. The AEF that was submitted to the source analysis resulted from an average of 114-116 artifact-free stimulus epochs across conditions. (There were no significant differences in the number of accepted epochs between stimuli [tone, syllable], stimulated ear [left, right], or group.) The baseline was corrected for each channel according to the mean value of the signal during the $100 \mathrm{msec}$ before the stimulus. For the analysis of the N100m response to tones and syllables, evoked fields were filtered using a band-pass from 1 to $30 \mathrm{~Hz}$ (second-order zero-phase shift, Butterworth filter, $12 \mathrm{~dB} / \mathrm{oct}$ ). $\mathrm{N} 100 \mathrm{~m}$ were determined within the first $300 \mathrm{msec}$ after stimulus onset only. A single equivalent current dipole (ECD) in a best-fitting local sphere was estimated separately for the left and the right hemisphere for the four conditions (tones delivered to the left ear, tones delivered to the right ear, syllables delivered to the left ear, syllables delivered to the right ear). Subsets of 37 channels over either the left or the right auditory areas were selected for source analysis. (Thirty-seven channels cover a circular area over the skull.) An ECD defined by dipole moment, orientation, and space coordinates was calculated for each sample point. The location of the ECD was estimated in a head-based coordinate system. The origin of this coordinate system was set at the midpoint of the medial-lateral axis (y axis) that joined the center points of the entrance to the acoustic meatus of the left and the right ears (positive toward the left ear). The posterior-anterior axis ( $\mathrm{x}$ axis) was oriented from the origin to the nasion (positive toward the nasion), and the inferiorsuperior axis ( $\mathrm{z}$ axis) was perpendicular to the $\mathrm{x}-\mathrm{y}$ plane (positive toward the vertex).

Analysis of the data was concentrated on the major component of the AEF, the N100m. Each N100m dipole parameter was represented by the median ${ }^{1}$ of seven dipole fits (24-msec interval) around the maximum of the root mean square (RMS) of the

\footnotetext{
${ }^{1}$ The median was chosen instead of the mean to determine a real dipole fit instead of an artificial one as obtained from averaging. The median of seven dipole fits was chosen instead of the root mean square peak to prevent the influence of another (e.g., a frontal source), which may have its onset shortly after the peak of the temporal N100 generator. In such a case of an overlap of two generators, a single dipole model results in insufficient stability and goodness of fit. The choice of a median of several fits ascertains that one or two unstable points will not affect the estimate of the source location.
}

magnetic field calculated across the respective subset of channels. The calculated values were accepted for further analysis when they satisfied the following source analysis and anatomic requirements: goodness of fit of the ECD model to the measurement of $>90 \%$, range of source coordinates within the 24-msec interval $<2 \mathrm{~cm}$; anterior-posterior value within $<2 \mathrm{~cm}$; anteriorposterior value within $\pm 3 \mathrm{~cm}$; medial-lateral value (distance to the midsagittal plane) $>2.5 \mathrm{~cm}$; and inferior-superior value between 3 and $8 \mathrm{~cm}$. The goodness of fit of the ECD model to the measured field, taken as indicator of the data quality, varied between 0.960 and 0.975 in the control group and 0.958 and 0.979 in the patient group. (This resulted in a mean of 0.969 within each group, $F<1$ ). The average confidence volume of the dipole fits was $258.1 \mathrm{~mm}^{3}$ for both groups.

Group- and stimulus-specific hemispheric asymmetries of the $\mathrm{N} 100 \mathrm{~m}$ were examined for the peak latency, the dipole strength, and the location of the $\mathrm{N} 100 \mathrm{~m}$ on the anterior-posterior, the medial-lateral, and the inferior-superior axes. Differences in these measures between group (schizophrenic patients, control subjects), stimulus type (tones, syllables), ear (the side of stimulation-i.e., the left or the right ear), and the hemisphere in which the $\mathrm{N} 100 \mathrm{~m}$ was localized relative to the ear of stimulation (ipsilateral, contralateral) were analyzed by means of repeatedmeasures analyses of variance. For comparison with the previous experiment (Rockstroh et al 1998), lateralization of N100m dipole strength was evaluated by means of a laterality index (LI) (difference of contralateral and ipsilateral scores divided by their sum). This LI was determined separately for stimuli presented to the left ear and for stimuli presented to the right ear-that is, the LI always refers to the ipsilateral-contralateral comparison to the same ear stimulus. Since hemispheric lateralization differs between male and female subjects, explorative analyses compared results for male and female subjects by the between-subjects factor gender to probe a possible impact of gender on the present results.

For interactions with degrees of freedom larger than 1, the degrees of freedom were corrected using the GreenhouseGeisser procedure to account for possible violations of the sphericity assumption. Means and standard deviations are reported.

\section{Results}

Figure 1 provides examples of typical auditory magnetic responses as evoked by tones and syllables in the ispilateral and contralateral hemisphere for two representative subjects, a schizophrenic patient and a control subject. Peaks around $100 \mathrm{msec}$ following stimulus onset are evident for tones and syllables, as are differences in peak latencies between tones and syllables. Larger contralateral than ipsilateral amplitudes are more obvious at distinct sensors for the control subject than for the schizophrenic patient.

\section{Latency of N100m}

In both groups, $\mathrm{N} 100 \mathrm{~m}$ peaked earlier over the hemisphere contralateral to the side of stimulation $(94.6 \pm 12.6 \mathrm{msec})$ 


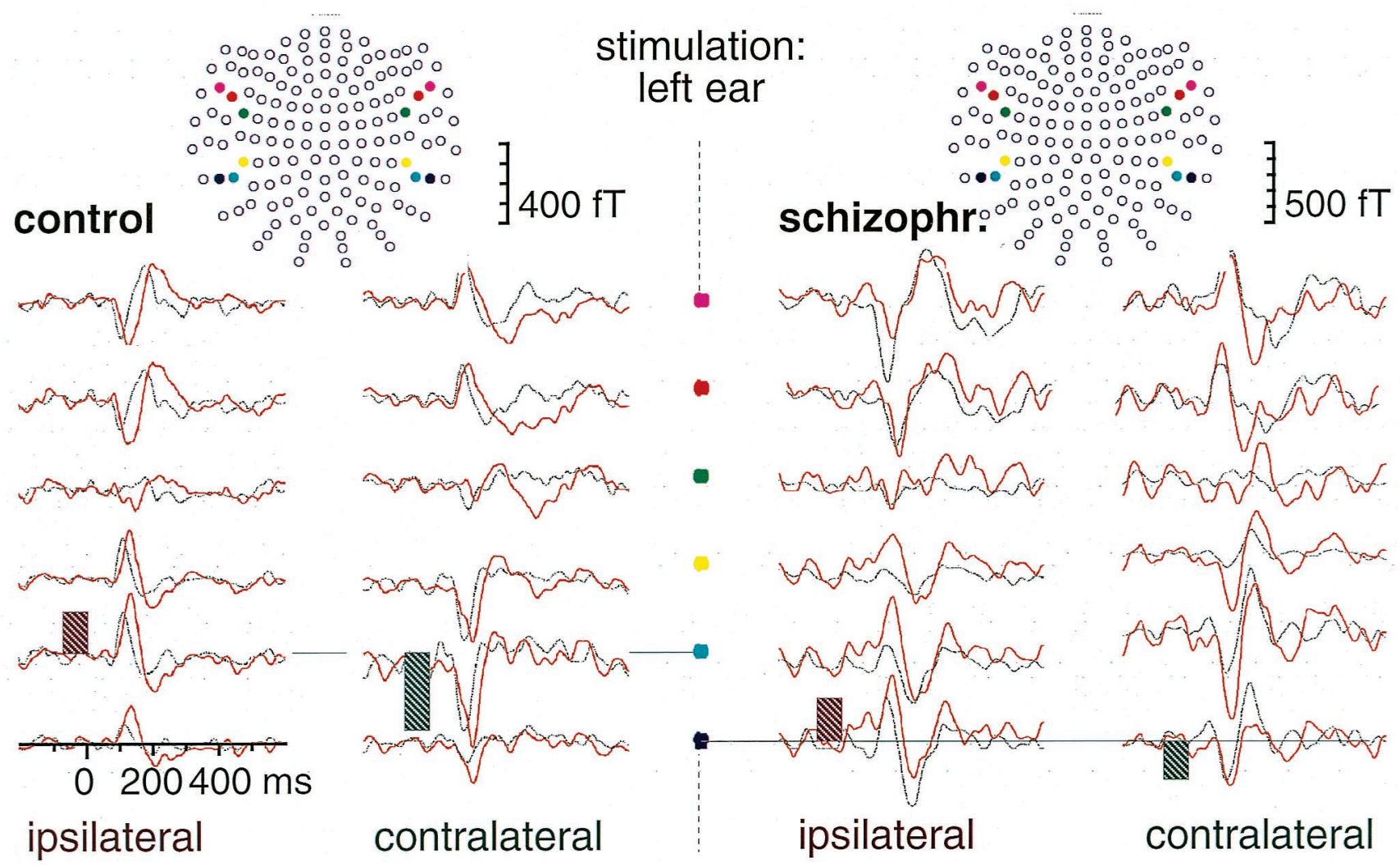

Figure 1. Averaged evoked magnetic responses in response to left ear stimuli are illustrated for a control subject and a schizophrenic patient for selected sensors over the hemisphere contralateral (right hemisphere) and ipsilateral (left hemisphere). Responses to tones (black lines) and syllables (red lines) differ in peak latencies and amplitudes. The hatched bars indicate the magnitude of tone-evoked $\mathrm{N} 100 \mathrm{~m}$ for the particular channel where $\mathrm{N} 100 \mathrm{~m}$ reaches the greatest amplitude per hemisphere. Note that the control subject, but not the schizophrenic subject, displays a contralateral dominance for the N100m elicited by the tones.

than over the ipsilateral hemisphere $[106.2 \pm 13.3$ msec; main effect hemisphere, $F(1,30)=212.4, p<$ $.001]$. It also peaked earlier in response to tones $(91.3 \pm$ $9.1 \mathrm{msec}$ ) than in response to syllables [109.4 $\pm 12.6 \mathrm{~ms}$; main effect stimulus type, $F(1,30)=369.9, p<.001]$. The contralateral $\mathrm{N} 100 \mathrm{~m}$ peaked earlier after left ear stimulation $(99.2 \pm 13.9 \mathrm{msec})$ than after right ear stimulation $[101.6 \pm 14.4 \mathrm{msec}$; main effect ear, $F(1,30)=9.8, p<.01]$, the more so following syllables than tones [stimulus type $\times$ ear $\times$ hemisphere, $F(1,30)=$ 5.6, $p<.05$; ear $\times$ hemisphere, $F(1,30)=5.5, p<.05$ ]. A marginally significant interaction, group $\times$ stimulus type $\times$ ear $[F(1,30)=3.9, p=.06]$, resulted from larger differences (with earlier contralateral $\mathrm{N} 100 \mathrm{~m}$ peak) in patients than in control subjects under all conditions except for syllables presented to the right ear, in response to which the latency differences between hemispheres were smallest in patients (Figure 2). Post hoc analyses confirmed a significant interaction, stimulus type $\times$ ear, for patients $[F(1,16)=12.8, p<.01]$ but not for control subjects $(F<1)^{2}$.

\section{Dipole Strength of N100m}

Both the raw signal power (RMS of the signal measured from 37 channels) and the modeled N100m dipole moment $(\mathrm{Q})$ showed a larger magnitude for tones than for syllables [main effect stimulus type, RMS, $F(1,30)=4.1$, $p=.05 ; \mathrm{Q}, F(1,30)=8.2, p<.01]$. Larger contralateral than ipsilateral auditory magnetic responses were confirmed by main effects hemisphere [RMS, $F(1,30)=92.2$, $p<.001 ; \mathrm{Q}, F(1,30)=22.2, p<.001]$. Tones-and to a lesser extent syllables-presented to the right ear pro-

\footnotetext{
2 The larger contralateral acceleration of the N100m latency in response to syllables presented to the left ear and the smaller asymmetry in response to syllables presented to the right ear were more pronounced in male than in female patients [for the patient group, stimulus type $\times$ ear, $F(1,15)=10.9, p<.01$ ], whereas asymmetries were similar and contrasts nonsignificant between male and female control subjects.
} 

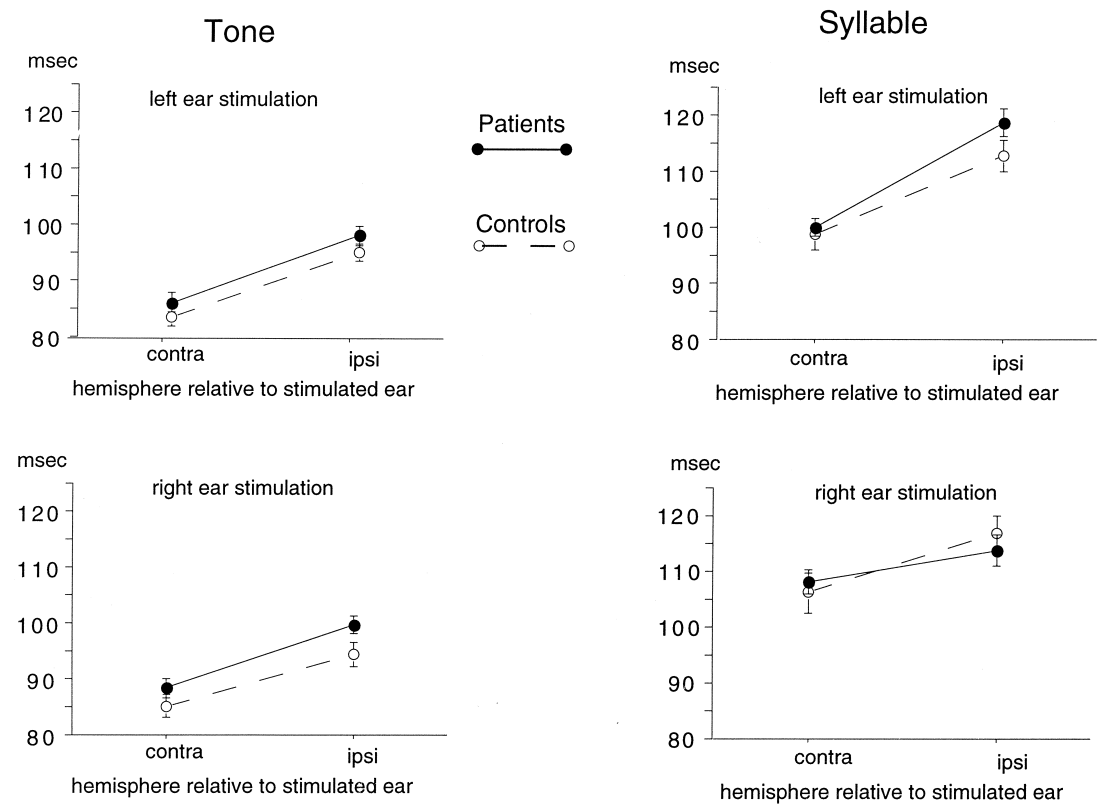

Figure 2. N100m latencies (in msec) for tones and syllables following left and right ear stimulation in patients and control subjects. Earlier N100m peaks contralateral to the stimulated ear are indicated by shorter latencies (msec ordinates). Both groups exhibit earlier contralateral N100m peaks in response to tones, and both groups show longer N100m latencies to syllables than to tones. Comparison of the right graphs illustrates that patients display almost no N100m latency differences between hemispheres in response to syllables presented to the right ear, but the most pronounced asymmetry following syllables presented to the left ear. This pattern of results suggests faster conduction velocity in the right hemisphere and slower velocity in the left hemisphere in patients.

duced more pronounced contralateral responses than stimuli presented to the left ear [stimulus type $\times$ ear $\times$ hemisphere: RMS, $F(1,30)=2.9, p<.1$; Q, $F(1,30)=$
5.8, $p<.05$; ear $\times$ hemisphere: RMS, $F(1,30)=6.8, p<$ $.05 ; \mathrm{Q}, F(1,30)=5.2, p<.05$; see also Figure 3].

Analyses of variance calculated with the LIs of the
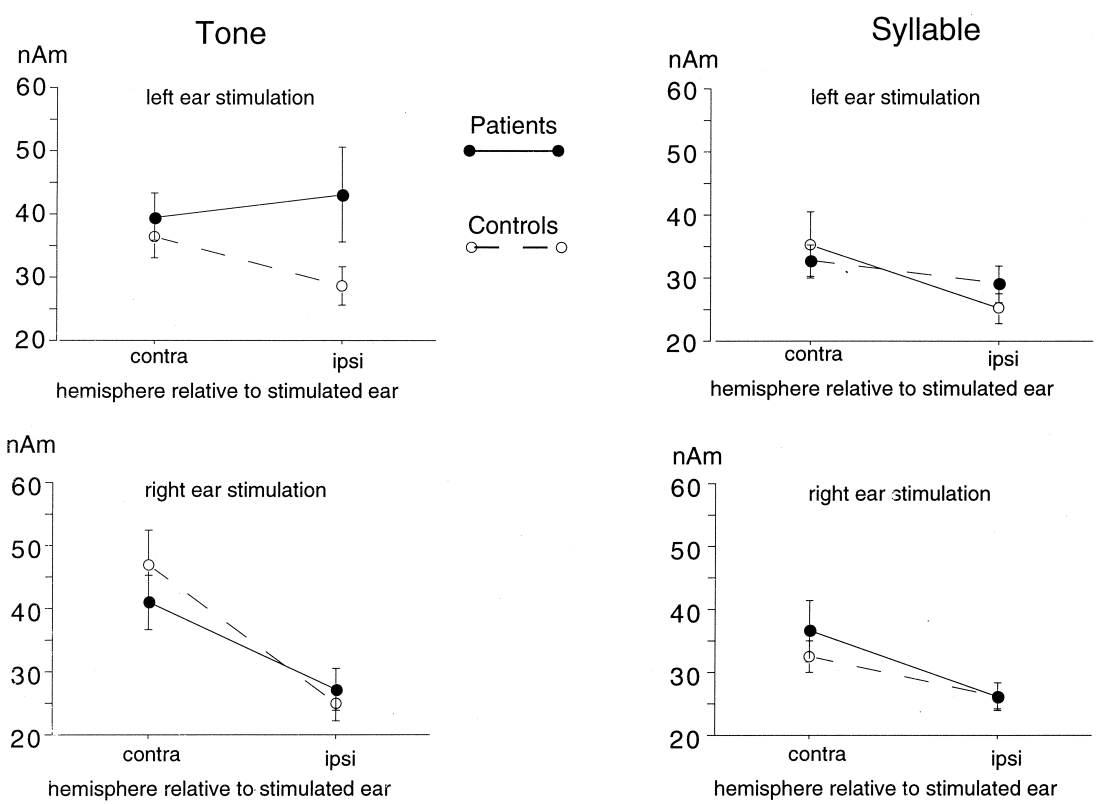

Figure 3. N100m dipole strength $(\mathrm{Q}$, in $\mathrm{nAm})$ for tones and syllables following left and right ear stimulation in patients and control subjects. Larger contralateral N100m dipole strength is evident for syllables and right ear tones, whereas the upper left graph indicates no asymmetry in patients following left ear tones. 
Table 1. Laterality Indices of N100m Dipole Strength Q, Averaged Separately for Group, Stimulus Type, and Ear of Stimulation

\begin{tabular}{lcccc}
\hline & \multicolumn{2}{c}{ Schizophrenic patients } & \multicolumn{2}{c}{ Control subjects } \\
& Left ear & Right ear & Left ear & Right ear \\
\hline Tone & .02 & .20 & .13 & .31 \\
& $(-.56-+.72)$ & $(-.20-+.61)$ & $(-.34-.48)$ & $(-.04-+.60)$ \\
Syllable & .07 & .14 & .13 & .11 \\
& $(-.39-+.40)$ & $(-.35-+.52)$ & $(-.38-+.67)$ & $(-.18-+.30)$ \\
\hline
\end{tabular}

The interindividual range of laterality indices is shown in parentheses. Positive values indicate larger contralateral than ipsilateral $\mathrm{Q}$, and negative values reversed asymmetry with larger $\mathrm{N} 100 \mathrm{~m}$ dipole strength in the hemisphere ipsilateral to the side of stimulation.

dipole moment $\mathrm{Q}$ confirmed the more pronounced asymmetries following tones by a significant main effect stimulus type $[F(1,30)=5.0, p<.05]$. A significant group $\times$ stimulus type interaction $[F(1,30)=4.3, p<.05]$ indicated more pronounced asymmetry in control subjects than in patients following tones, but negligible group differences following syllables. The trend for an interaction group $\times$ stimulus type $\times$ ear $[F(1,30)=3.3, p<.07]$ resulted from the smallest asymmetry in patients in response to left ear tones, and the largest asymmetry in control subjects in response to right ear tones. In addition, patients showed slightly more pronounced asymmetries than control subjects in response to right ear syllables; see also Table 1). Post hoc tests confirmed a significant difference between $\mathrm{N} 100 \mathrm{~m}$ asymmetries in response to left and right ear tones in control subjects $[t(14)=2.4, p<$ $.05]$ and a trend in patients $[t(16)=2.0, p=.06]$, whereas all other comparisons were nonsignificant.

In response to tones presented to the right ear, all control subjects and 13 of the 17 patients (24\%) showed an asymmetry of the dipole moment $\mathrm{Q}$, with larger $\mathrm{Q}$ in the contralateral hemisphere $\left(\chi^{2}=4.0\right.$, Fisher exact $\left.p=.1\right)$. In response to tones presented to the left ear, asymmetry with contralateral predominance was found in 13 of the 15 control subjects but only in eight of the 17 patients $(47 \%$; $\chi^{2}=5.2, p<.05$; Fisher exact $p<.05$; see Table 1 and Figure 3 for interindividual variability of LIs) ${ }^{3}$. No significant group differences were obtained in response to syllables presented to the right ear, when 10 of 15 control subjects and 11 of 17 patients showed contralateral predominance of Q, and in response to left ear syllables, when 11 control subjects and 10 patients displayed the expected asymmetry.

In patients the reduced or reverse asymmetry of the $\mathrm{N} 100 \mathrm{~m}$ dipole strength $\mathrm{Q}$ following left ear tones correlated with negative symptoms (SANS, $r=-.54, p<.05$; PANSS-N, $r=-.47, p<.1$ ), with longer hospitalization

\footnotetext{
${ }^{3}$ The same results were obtained if lateral asymmetry was determined as difference between contralateral minus ipsilateral Q scores: for tones presented to the right ear, $\chi^{2}=2.9$, ns, and for tones presented to the left ear, $\chi^{2}=4.2, p<.05$.
}

$(r=-.52, p<.05)$, and with higher neuroleptic doses (chlorpromazinequivalent, $r=-.55, p<.05$ ). Negative correlation coefficients indicated that smaller asymmetry (LI) was associated with more pronounced negative symptoms, longer overall hospitalization, and higher daily dosage of neuroleptic medication. No significant correlation coefficients were obtained for LI scores with positive symptom scores, in response to right ear stimulation or in response to syllables.

The overall dipole strength $\mathrm{Q}$ and the raw signal power RMS were smaller in female subjects than in male subjects [gender: $\mathrm{Q}, F(1,30)=4.7, p<.05$; RMS, $F(1,30)=4.1$, $p=.05]$. On average, male subjects displayed virtually no asymmetry in response to tones presented to the left ear (mean LI $=.001$, range $-.56-+.37$ ), whereas asymmetry in response to tones presented to the right ear $(\mathrm{LI}=.24$, range $-.20-+.61)$ was similar to asymmetries in response to syllables (mean LIs .25 [left ear stimuli] and .21 [right ear stimuli]). In contrast, female subjects displayed the smallest asymmetry on the average in response to syllables presented to the right ear (mean LI $=.16$, range $-.18-$ +.40 ), but asymmetries similar to those of male subjects for all other conditions (mean LIs .21-.26). The genderspecific asymmetries were confirmed by the interaction gender $\times$ stimulus type $[F(1,30)=13.6, p<.01$; $F(1,30)=10.4, p<.01]$ for the interaction including the hemisphere as a factor. Post hoc tests confirmed the significant difference between tones presented to the left and the right ears in male subjects $[t(20)=5.1, p<.05]$ and a significant gender difference in the LI for tones presented to the left ear $[t(30)=2.3, p<.05]$.

\section{Dipole Location of N100m}

In control subjects, the N100m was located more anterior in the right hemisphere (following stimuli presented to the left ear) and less anterior in the left hemisphere (in response to right ear stimuli). In contrast, patients did not show hemispheric asymmetry in the location of the $\mathrm{N} 100 \mathrm{~m}$ in the anterior-posterior direction (Figure 4). Although groups did not differ in their location of the $\mathrm{N} 100 \mathrm{~m}$ in the anterior-posterior direction in the right hemisphere (contralateral to left ear stimuli), the patients' N100 in the left hemisphere (which is contralateral to right ear stimuli) was notably more anterior than that of control subjects $[t(30)=3.0, p<.01]$. This group difference resulted in the interactions group $\times$ ear $\times$ hemisphere $[F(1,30)=5.7, p<.05]$ and ear $\times$ hemisphere $[F(1,30)=$ 9.2, $p<.01]$, whereas the main effect group failed to reach significance $[F(1,30)=2.8, p=.1]$. Only in the control group did the difference between the $\mathrm{N} 100 \mathrm{~m}$ locations for left and right ear stimuli reach significance $[t(14)=3.9, p<.01]$. In both groups, the N100m was 


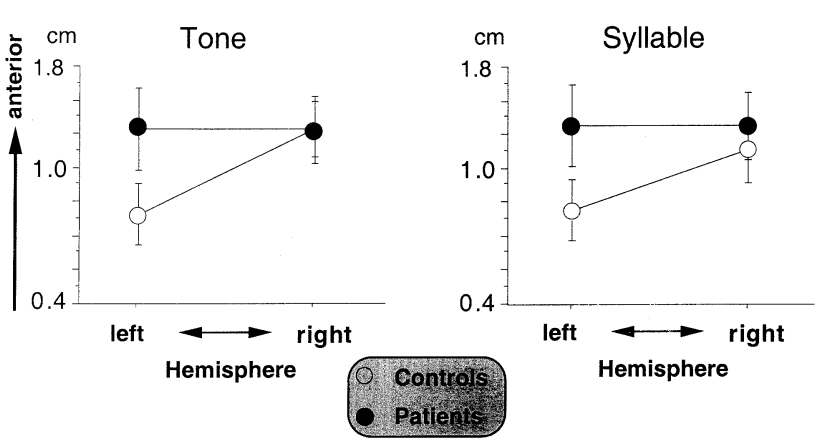

Figure 4. Location of the N100m dipole in the posterior-anterior direction contralateral to tone and syllable stimuli. Dipole locations are illustrated for the left (contralateral to right ear stimuli) and the right (contralateral to left ear stimuli) hemispheres in schizophrenic patients and control subjects. Higher values on the ordinate indicate a more anterior location of the N100m source.

generally located more anterior for syllables than for tones [stimulus type, $F(1,30)=13.1, p<.01]$.

The location of the N100m did not differ significantly between groups on the medial-lateral and inferior-superior planes. The N100m was more medial to tones than to syllables [stimulus type, $F(1,30)=10.25, p<.01$ ], and more medial following left ear stimuli than right ear stimuli [stimulus type $\times$ ear $\times$ hemisphere, $F(1,30)=7.4$, $p<.05]$. The $\mathrm{N} 100 \mathrm{~m}$ was more superior ipsilateral to left ear stimuli [for tones, $t(31)=2.1, p<.05$; for syllables, $t(31)=4.1, p<.01]$ and more superior contralateral to right ear stimuli [for tones, $t(31)=2.4, p<.05$; for syllables, $t(31)=2.9, p<.01]$. This interaction [ear $\times$ hemisphere, $F(1,30)=15.64, p<.001$; hemisphere, $F(1,30)=12.90, p<.01]$ was more pronounced for syllables than for tones [stimulus type $\times$ ear $\times$ hemisphere, $F(1.30)=5.7, p<.05]$. It suggests that the location of the $\mathrm{N} 100 \mathrm{~m}$ is more superior in the left hemisphere than in the right hemisphere for syllable processing.

\section{Discussion}

The two main goals of this study were 1) to substantiate the reduced hemispheric asymmetry of the AEFs to $1000-\mathrm{Hz}$ tones in schizophrenic patients (Rockstroh et al 1998) by comparing right and left ear stimulation in a larger sample of patients and control subjects and 2) to explore the range of hemispheric asymmetry in schizophrenia by comparing laterality measures in response to simple tones and to verbal material (syllables).

Single ECDs could be fitted in all subjects and for all conditions. The peak latencies were shorter and the dipole strengths larger for contralateral than for ipsilateral $\mathrm{N} 100 \mathrm{~m}$ dipoles, the differences being similar to those reported by Mäkelä et al (1993). For the processing of
$1000-\mathrm{Hz}$ tones, the expected functional asymmetry was replicated for control subjects, the asymmetry being even more pronounced in response to tones presented to the right ear $(100 \%$ of the control group exhibiting contralateral predominance) than in response to tones presented to the left ear (87\% of the control group exhibiting contralateral predominance). In contrast to the previous study, only $24 \%$ of this sample of schizophrenic patients displayed a reversed asymmetry. However, a marked deviation from the normal asymmetry was found in the patient group in response to left ear stimulation, with almost $50 \%$ of the sample displaying a reversed asymmetry. Thus, only a proportion of patients with a schizophrenic diagnosis display changes of hemispheric lateralization beyond the range of control subjects. It seems interesting to notice that the reduced or reversed asymmetry in this study varied with negative symptoms, neuroleptic dosage, and hospitalization time (i.e., with indications of more severe impairment).

Reduced or reversed asymmetry of a functional indicant of auditory processing should be the consequence of predominating processing of the stimulus either in the ipsilateral hemisphere or in both hemispheres. It is tempting to explain the reduced or reversed asymmetry in the processing of left ear tones in schizophrenic patients as a compensation for a dysfunction of left hemispheric processing, as a bias toward right hemispheric processing, as suggested for schizophrenic patients by Woodruff et al (1997).

Altered asymmetry was more prominent in patients in a more severe state (higher negative symptoms, longer hospitalization, and higher neuroleptic doses). Other studies did not find a correlation between medication and functional laterality (e.g., Eaton et al 1979), so that our sample size seems insufficient to draw conclusions, leaving the contribution of neuroleptic medication to functional asymmetry of the N100m for further scrutiny.

The sources of the N100m in response to both stimuli were located more anterior on the anterior-posterior axis in patients, relative to control subjects, and patients-in contrast to control subjects-did not show an asymmetry between the anterior locations of the N100m in the left and the right hemispheres. The asymmetry displayed by control subjects is in line with findings of Reite et al (1989) and Nakasato et al (1995) of more anterior right and more posterior left hemispheric N100m sources, this asymmetry being larger in male subjects than in female subjects. However, both male and female patients in our study displayed more anterior left hemispheric sources, in contrast to the results of Reite et al (1999).

We explored the range of hemispheric asymmetries by comparing the lateralization of the $\mathrm{N} 100 \mathrm{~m}$ to simple tones and syllables. This comparison revealed less lateralized 
processing of syllables than of tones in both groups: In schizophrenic patients and in control subjects the mean LIs were smaller, particularly for right ear stimuli, when syllables were processed than when tones were presented, and the interindividual range of LIs was also smaller. Less prominent asymmetry may be the result of the generally smaller (RMS and dipole strength) and later (latency) $\mathrm{N} 100 \mathrm{~m}$ responses. Less asymmetry may also be the consequence of a right hemispheric bias in speech processing, as described by Woodruff et al (1997) for schizophrenic patients. However, such an explanation would hold for both groups in our study. In any case, it seems interesting to notice that schizophrenic patients and control subjects did not differ in their lateralized processing of syllables. For words, too, we did not find indications for a left hemispheric deficit in schizophrenics (Mohr et al, in press, under revision). This would be in contrast to the assumption of a left hemispheric dysfunction of languagerelated processing in schizophrenia. If left hemispheric, language-related dysfunction is to be assumed in schizophrenia, it might affect or involve higher levels like discourse (Frith 1993; Harrow and Quinlan 1985) rather than basic processing stages such as passive listening to consonant-vowel syllables or phonemes.

Differences in the N100m latency between patients and control subjects, too, suggest an altered hemispheric functioning in schizophrenia. Pronounced differences of the N100m latency between left and right stimulation were found in patients, but differences were less in control subjects. Contralateral N100m peaked earlier following left ear stimulation. This might be comparable to a left ear advantage of the N100 determined from dichotic listening tasks, for which Tenke et al (1993) had found a left ear advantage in $70 \%$ of the normal subjects. We assume that information transfer from the left to the right hemisphere was very fast in schizophrenic patients (latency difference $=5 \mathrm{msec}$ ), whereas the information from the right to the left hemisphere after left ear stimulation was delayed (latency difference $=20 \mathrm{msec}$ ). In healthy control subjects the latency or transfer difference was similar in left (14 $\mathrm{msec})$ and right $(10 \mathrm{msec})$ ear stimulation. This transfer difference may lead to the conclusion that the time each hemisphere takes to transfer information to the other hemisphere (conduction velocity) differs between the two cerebral hemispheres in schizophrenic patients, but is similar in control subjects (Miller 1996; Tomer 1990). However, in our study the difference in conduction velocity between the two hemispheres only applies for syllables, not for simple tones. During tone processing, no group differences appeared with respect to left or right ear stimulation. Larger differences between the right and left hemisphere in schizophrenic patients are consistent with previous data (Mohr et al, under revision) showing a highly significant right ear advantage for words in schizophrenic patients after monaural stimulation with spoken words. In that experiment, the right ear advantage for verbal material was more pronounced in schizophrenic than in control subjects, as in the latency data of this study. In addition, we found evidence of impaired interhemispheric cooperation in schizophrenic patients during word processing (Mohr et al, in press), which may also be suggested by the data on syllable processing discussed here. The slower conduction velocity from the right to the left hemisphere may have been influenced by morphological deviations, as they were indicated by the reduced asymmetry of the $\mathrm{N} 100 \mathrm{~m}$ dipole on the anterior-posterior plane in schizophrenic patients. As reported in other studies, the cortical area that may be involved in auditory processing may be the superior temporal gyrus, which also plays an important role in language processing.

In sum, this study confirmed alterations of functional asymmetry during auditory processing in schizophrenic patients-more so in the processing of simple tones than in the processing of syllables and more so in response to left ear stimulation than in response to right ear stimulation. Group differences in the laterality pattern and in the capability of the two hemispheres to transfer information may result from deviations in brain structure of schizophrenic patients.

Research was supported by the Deutsche Forschungsgemeinschaft (Ro 805/11) and the Volkswagen-Stiftung.

The authors gratefully acknowledge the assistance of Drs. H. Watzl and K. Pröpster in establishing the diagnostics and clinical status of the patients, and of Dr. E. Diesch and S. Heim inr generating the syllable stimuli.

\section{References}

Andreasen N (1981): Scale for the Assessment of Negative Symptoms: SANS. Iowa City: University of Iowa.

Barta PE, Pearlson GD, Brill LB, Royall R, McGilchrist IK, Pulver AE, et al (1997): Planum temporale asymmetry reversal in schiyophrenia: Replication and relationship to gray matter abnormalities. Am J Psychiatry 154:661-667.

Bilder R, Wu H, Bogerts B, Ashtari M, Robinson D, Woerner M, et al (1999): Cerebral volume asymmetries in schizophrenia and mooed disorders: A quantitative magnetic resonance imaging study. Int J Psychophysiol 34:197-206.

Crow TJ (1990): Temporal lobe asymmetries as the key to the etiology of schizophrenia. Schizophr Bull 16:433-443.

Crow TJ (1997a): Is schizophrenia the price that Homo sapiens pays for language? Schizophr Res 28:127-141.

Crow TJ (1997b): Schizophrenia as failure of hemispheric dominance for language. Trends Neurosci 20:339-343.

Crow TJ (1998): Nuclear schizophrenic symptoms as a window 
on the relationship between thought and speech. Br J Psychiatry 173:303-309.

Crow TJ, Ball J, Bloom SR, Brown R, Bruton CJ, Colter N, et al (1989): Schizophrenia as an anomaly of development of cerebral asymmetry. A postmortem study and a proposal concerning the genetic basis of the disease. Arch Gen Psychiatry 46:1145-1150.

DeLisi LE (1999): Defining the course of brain structural change and plasticity in schizophrenia. Psychiatry Res 92:1-9.

Eaton EM, Busk J, Maloney MP, Sloane RB, Whipple K, White K (1979): Hemispheric dysfunction in schizophrenia: Assessment by visual perception tasks. Psychiatry Res 1:325-332.

Eulitz C, Diesch E, Pantev C, Hampson S, Elbert T (1995): Magnetic and electric brain activity evoked by the processing of tone and vowel stimuli. J Neurosci 15:2748-2755.

Falkai P, Bogerts B, Schneider T, Greve B, Pfeiffer U, Pilz K, et al (1995): Disturbed planum temporae asymmetry in schizophrenia: A quantitative post-mortem study. Schizophr Res 14:161-176.

Flor-Henry P (1989): Psychopathology and hemispheric specialization: Left hemispheric dysfunction in schizophrenia, psychopathy, hysteria and the obsessional syndrome. In: Boller J, Grafman J, editors. Handbook of Neuropsychology, Vol 3. Amsterdam: Elsevier, 477-494.

Frith CD (1993): The Cognitive Neuropsychology of Schizophrenia. Hillsdale, NJ: Erlbaum.

Galderisi S, Bucci P, Mucci A, D'Amato A, Conforti R, Maj M (1999): "Simple schizophrenia": A controlled MRI and clinical/neuropsychological study. Psychiatry Res 91:175-184.

Geschwind N, Levitsky W (1968): Human brain: Left-right asymmetries in the temporal speech region. Science 161:186187.

Gootjes L, Raji T, Salmelin R, Hari R (1999): Left-hemisphere dominance for processing of vowels: A whole-scalp neuromagnetic study. Neuroreport 10:2987-2991.

Gur RE (1978): Left hemisphere dysfunction and overactivation in schizophrenia. J Abnorm Psychol 87:226-238.

Hajek M, Huonker R, Boehle C, Volz HP, Nowak H, Sauer H (1997): Abnormalities of auditory evoked magnetic fields and structural changes in the left hemisphere of male schizophrenics - a magnetoencephalographic-magnetic resonance imaging study. Biol Psychiatry 42:609-616.

Harrow M, Quinlan DM (1985): Disordered Thinking in Schizophrenic Psychopathology. New York: Gardner.

Hellige JB (1993): Hemispheric Asymmetry: What's Right and What's Left? Cambridge, MA: Harvard University Press.

Kanno A, Nakasato N, Hatanaka K, Ohtomo S, Suzuki K, Fujiwara S, et al (1998): Interhemispheric asymmetry exists in female in the N100m source position of the auditory evoked magnetic fields. No To Shinkei 50:367-371.

Kay S, Fiszbein A, Opler L (1987): The Positive and Negative Symptom Scale (PANSS) for schizophrenia. Schizophr Bull 13:261-275.

Kreitschmann-Andermahr I, Rosburg T, Meier T, Volz HP, Nowak H, Sauer H (1999): Impaired processing in male patients with schizophrenia: A magnetoencephalographic study of auditory mismatch detection. Schizophr Res 35:121129.

Lukoff D, Nuechterlein K, Ventura J (1986): Appendix A.
Manual for Expanded Brief Psychiatric Rating Scale (BPRS). Schizophr Bull 12:594-602.

Magaro PA, Chamrad DL (1983): Information processing and lateralization in schizophrenia. Biol Psychiatry 18:29.

Mäkelä JP, Ahonen A, Hämäläinen M, Hari R, Ilmoniemi R, Kajola M, et al (1993): Functional differences between auditory cortices of the two hemispheres revealed by wholehead neuromagnetic recordings. Hum Brain Mapp 1:48-56.

Miller R (1996): Axonal Conduction Time and Human Cerebral Laterality. Amsterdam: Harwood.

Mohr B, Heim S, Pulvermüller F, Rockstroh B (under revision): Functional asymmetry during auditory speech processing in schizophrenic patients. Schizophr Res.

Mohr B, Pulvermüller F, Cohen R, Rockstroh B (in press): Interhemispheric cooperation during word processing: Evidence for callosal transfer dysfunction in schizophrenic patients. Schizophr Res.

Nakasato N, Fujiya S, Seki K, Kawamura T, Matani A, Tamura I, et al (1995): Functional localization of bilateral auditory cortices using an MRI-linked whole-head magnetoencephalography (MEG) system. Electroencephalogr Clin Neurophysiol 94:183-190.

Oldfield R (1971): The assessment and analysis of handedness: The Edinburgh Questionnaire. Neuropsychologia 9:97-113.

Overall JE, Gorham DR (1962): The Brief Psychiatric Rating Scale. Psychol Rep 10:419-427.

Pantev C, Ross B, Berg P, Elbert, T, Rockstroh B (1998): Study of the human auditory cortices using a whole-head magnetometer: Left vs. right hemisphere and ipsilateral vs. contralateral stimulation. Audiol Neurootol 3:183-190.

Pearlson GD, Marsh L (1999): Structural brain imaging in schizophrenia: A selective review. Biol Psychiatry 46:627649.

Petty RG, Barta PE, Pearlson GD, McGilchrist IK, Lewis RW, Tien AY, et al (1995): Reversal of asymmetry of the planum temporale in schizophrenia. Am J Psychiatry 152:715-721.

Reite M, Sheeder J, Teale P, Adams M, Richardson D, Simon J, et al (1997): Magnetic source imaging evidence of sex differences in cerebral lateralization in schizophrenia. Arch Gen Psychiatry 54:433-440.

Reite M, Teale P, Goldstein L, Whalen J, Linnville S (1989): Late auditory sources may differ in the left hemisphere of schizophrenic patients: A preliminary report. Arch Gen Psychiatry 46:565-572.

Reite M, Teale P, Rojas DC (1999): Magnetoencephalography: Applications in psychiatry. Biol Psychiatry 45:1553-1563.

Rinne T, Alho K, Alku P, Holi M, Sinkkonen J, Virtanen J, et al (1999): Analysis of speech sounds is left-hemisphere predominant at 100-150 ms after sound onset. Neuroreport 10:11131117.

Rockstroh B, Clementz BC, Pantev C, Blumenfeld LA, Sterr AM, McDowell J, Elbert T (1998): Failure of dominant left-hemispheric activation to right-ear stimulation in schizophrenia. Neuroreport 9:3819-3822.

Rockstroh B, Elbert T, Berg P (1997): Die Untersuchung von Strukturen und Funktionen des Gehirns in der experimentellen Psychopathologie am Beispiel der Schizophrenien. In: Rockstroh B, Elbert T, Watzl TH, editors. Impulse für die Klinische Psychologie. Göttingen, Germany: Hogrefe, 1-29. 
Sauer H, Rosburg T, Kreitschmann-Andermahr I, Volz HP, Huonker R, Nowak H, Hajek M (1998): Geschlechtsspezifische Unterschiede der Hemisphärenlatera-lisation bei Schizophrenien? Nervenarzt 69:249-256.

Tenke CE, Bruder GE, Towey JP, Leite P, Siditis JJ (1993): Correspondence between brain ERP and behavioral asymmetries in a dichotic complex tone test. Psychophysiology 30:62-70.

Tiihonen J, Katila H, Pekkonen E, Jääskeläinen IP, Huotilainen M, Aronen HJ, et al (1998): Reversal of cerebral asymmetry in schizophrenia measured with magnetoencephalography. Schizophr Res 30:209-219.

Tomer R (1990): Neuroleptic effects on interhemispheric and intrahemispheric performance of tactile discrimination tasks by schizophrenic patients. Psychiatry Res 32:289-296.

Wing JK, Cooper JE, Sartorius N (1974): Measurement and Classification of Psychiatric Symptoms. London: Cambridge University Press.

Witelson SF, Kigar DL (1992): Sylvian fissure morphology and asymmetry in men and women: Bilateral differences in relation to handedness in men. J Comp Neurol 323:326-340.

Woodruff PW, Wright IC, Brammer M, Bullmore ET, Howard R, David AS, et al (1997): Altered lateralisation of auditory cortical response to external speech in schizophrenia. Schizophr Res 24:173. 